\title{
USO DE DOBLE COLGAJO DIEP PARA RECONSTRUCCIÓN DE EXTREMIDAD INFERIOR*
}

\author{
Drs. Ricardo Yáñez M. ${ }^{1}$, Álvaro Cuadra C. ${ }^{1}$, Claudio Guerra S. ${ }^{1}$, \\ Susana Searle F. ${ }^{1}$, Bruno Dagnino U. ${ }^{1}$
}

1 Sección de Cirugía Plástica y Reconstructiva Pontificia Universidad Católica de Chile. Santiago, Chile.

\begin{abstract}
Double DIEP flap for lower extremities reconstruction

Introduction: A soft tissue defect considering the extent, location, depth and involved structures can be a complex task, leading to search for unusual reconstructive alternatives. Case report: Puerperal woman, 21 years, previously healthy, admitted for septic shock and skin necrosis of both extremities secondary to purpura fulminans. Escharectomy was performed and the final defect was $27 \%$ of total body surface, corresponding to necrotic areas of both superior and lower extremities. Is remarkable the presence of musculocutaneous perforating vessels thrombosis and segmental muscular necrosis in legs and interosseous muscles necrosis in hands. In upper extremity coverage was performed with dermoepidermal grafts. To cover peroneal malleolus and feet dorsum, whereas there were no regional or local alternatives, we realize a double DIEP flap. Flap elevation of bilateral DIEP flap was performed simultaneously for two surgical teams. The patient had no complications and was discharged with complete soft tissue coverage.
\end{abstract}

Key words: Double DIEP flap, lower limb reconstruction, microsurgery.

\section{Resumen}

Introducción: Un defecto de cobertura extenso de extremidades inferiores (EEII), considerando ubicación, profundidad y estructuras involucradas es de una alta complejidad y puede llevar a buscar alternativas reconstructivas poco habituales. Caso clínico: Paciente de 21 años, puérpera, ingresa por shock séptico y necrosis cutánea extensa de extremidades secundario a un purpura fulminans. Se realiza escarectomía y el defecto resultante es de $27 \%$ de superficie corporal, correspondiendo a zonas necróticas en ambas extremidades, superiores e inferiores. Destaca la presencia de trombosis de vasos perforantes musculocutáneos, necrosis muscular segmentaria en piernas y de musculatura interósea en manos. En extremidades superiores se realizó cobertura con injertos dermoepidérmicos. Para la exposición de ambos maléolos peroneos y dorso de pies, considerando que no existen alternativas locales ni regionales, se decide realizar un colgajo DIEP bilateral; se eleva en un tiempo, con dos equipos quirúrgicos simultáneos. La anastomosis microquirúrgica se realizó a los vasos tibiales de cada extremidad. La evolución postoperatoria fue favorable. La paciente es dada de alta en buenas condiciones generales, extubada, con cobertura cutánea completa.

Palabras clave: Doble colgajo DIEP, reconstrucción extremidad inferior, microcirugía.

* Recibido el 1 de diciembre de 2014 y aceptado para publicación el 17 de enero de 2015 .

Los autores no refieren conflictos de interés.

Correspondencia: Dr. Ricardo Yáñez M.

ricardoyanezm@gmail.com 


\section{Introducción}

Existen variadas causas de necrosis cutáneas, que van desde lesiones producidas por traumatismos y quemaduras, patologías vasculares e infecciosas hasta algunas causas mucho menos frecuentes como las secundarias a enfermedades del mesénquima. La cobertura del defecto, considerando la extensión, ubicación, profundidad y estructuras involucradas es de una alta complejidad, que puede llevar a buscar alternativas reconstructivas poco habituales ${ }^{1,2}$.

El tratamiento del déficit de cobertura va desde el uso de injertos hasta el uso de distintos tipos de colgajos, dentro de estos, los colgajos perforantes se han hecho muy populares en los últimos años logrando excelentes resultados debido a que poseen una piel plegable y fácilmente moldeable con mínima morbilidad estética y funcional en la zona dadora $^{3}$. En 1989, Koshima y Soeda, reportaron la primera aplicación clínica de un colgajo perforante de arteria epigástrica inferior profunda (DIEP) demostrando que podían tomar la misma cantidad de piel y tejido graso que el colgajo TRAM, pero sin sacrificar los músculos rectos abdominales ${ }^{4}$. Posteriormente Allen y Treece reportaron 22 reconstrucciones mamarias exitosas con colgajo libre DIEP y finalmente Blondeel populariza su uso en reconstrucción mamaria autóloga $a^{5,6}$.

El objetivo de este trabajo es presentar el caso de una paciente que ingresa a la unidad de cuidados intensivos presentando extensa necrosis cutánea de extremidades superiores e inferiores, que requiere de múltiples aseos quirúrgicos y cobertura de los defectos producidos por pérdidas cutáneas debido a las cirugías, en la cual se utiliza un colgajo DIEP doble para cubrir ambos maléolos peroneos y dorso de ambos pies.

\section{Caso clínico}

Paciente de 21 años, puérpera de dos semanas, parto vaginal sin incidentes, sin antecedentes mórbidos de importancia. Ingresa derivada desde otro hospital por cuadro de dos semanas de evolución caracterizado por compromiso del estado general, palidez, disnea, cianosis y fiebre. A su ingreso al hospital de origen destacaba compromiso de conciencia, hipotensión, fiebre, livideces y flictenas en las extremidades superiores e inferiores. Los hemocultivos inicialmente son negativos y se inicia terapia antibiótica empírica logrando buena respuesta. Su evolución fue hacia la mejoría desde el punto de vista general, sin embargo, las lesiones descritas en las extremidades progresan en exten- sión y profundidad llegando a constituirse necrosis cutánea extensa. Se realiza escarectomía tangencial en una de ellas y posteriormente se decide traslado a nuestro centro para estudio y tratamiento de su cuadro médico y resolución quirúrgica de sus lesiones con cobertura definitiva de éstas. De los exámenes destacaba hipocomplementemia, bicitopenia (anemia y trombocitopenia), estudio inmunológico negativo (ANA, ANCA, MPO, PR3, anti-DNA, ENA y FR), estudio de imágenes sin hallazgos patológicos. En hemocultivos se aísla un Staphylococcus aureus y en cultivo de las lesiones cutáneas un Enterococcus faecium por lo que se ajusta tratamiento antibiótico. El diagóstico fue un purpura fulminans, destacando shock séptico de foco cutáneo, bicitopenia, insuficiencia renal aguda y falla hepática recuperada; permanece en ventilación mecánica y requiere de drogas vasoactivas.

Se realiza escarectomía profunda hasta plano fascial y muscular, obteniendo un defecto de cobertura de $27 \%$ de la superficie corporal total (Figuras 1 y 2). Las lesiones se restringen a las extremidades respetando tronco y cabeza. Destacaba la presencia de trombosis de vasos perforantes musculocutáneos, necrosis de tendones extensores de ambas manos y de ambos pies asociado a necrosis muscular segmentaria en parte de la pierna izquierda y de musculatura interósea en ambas manos. Se realizan múltiples aseos quirúrgicos y autoinjertos de espesor parcial expandidos 3:1 y en láminas fenestradas para cobertura de extremidades superiores.

Para la cobertura de la exposición de ambos maléolos peroneos y dorso de ambos pies se busca una alternativa de cobertura. Colgajos locales y de otros sitios en extremidades inferiores fueron descartados por el compromiso extenso de estas, por lo que, considerando el excedente cutáneo en esta paciente puérpera fue una alternativa válida el colgajo DIEP bilateral. Teniendo en cuenta el compromiso de vasos perforantes, se realiza previamente una arteriografía para determinar la permeabilidad de los ejes vasculares de las piernas y pies, se marcan las perforantes periumbilicales con Doppler $8 \mathrm{Mhz}$ (Sonotrax ${ }^{\mathrm{TM}}$ ) y luego se levanta el colgajo DIEP bilateral en un tiempo quirúrgico con dos equipos quirúrgicos simultáneos (Figura 3). En la extremidad inferior derecha se realiza una anastomosis término-terminal de los vasos epigástricos profundos derechos a la arteria y vena tibial anterior derecha; en la extremidad inferior izquierda se realiza anastomosis término-lateral a la arteria tibial posterior y término-terminal a las dos venas comitantes izquierdas simultáneamente. La evolución postoperatoria fue sin incidentes, salvo 
pequeña epidermólisis marginal en el borde de uno de los colgajos logrando con esto una cobertura completa de las zonas sometidas a escarectomía quedando pequeñas zonas cruentas en ambas extremidades que se manejaron con curaciones avanzadas (Figura 4).

La paciente es dada de alta a su hospital de origen en buenas condiciones generales, extubada, con cobertura cutánea adecuada para continuar tratamiento antibiótico y rehabilitación.
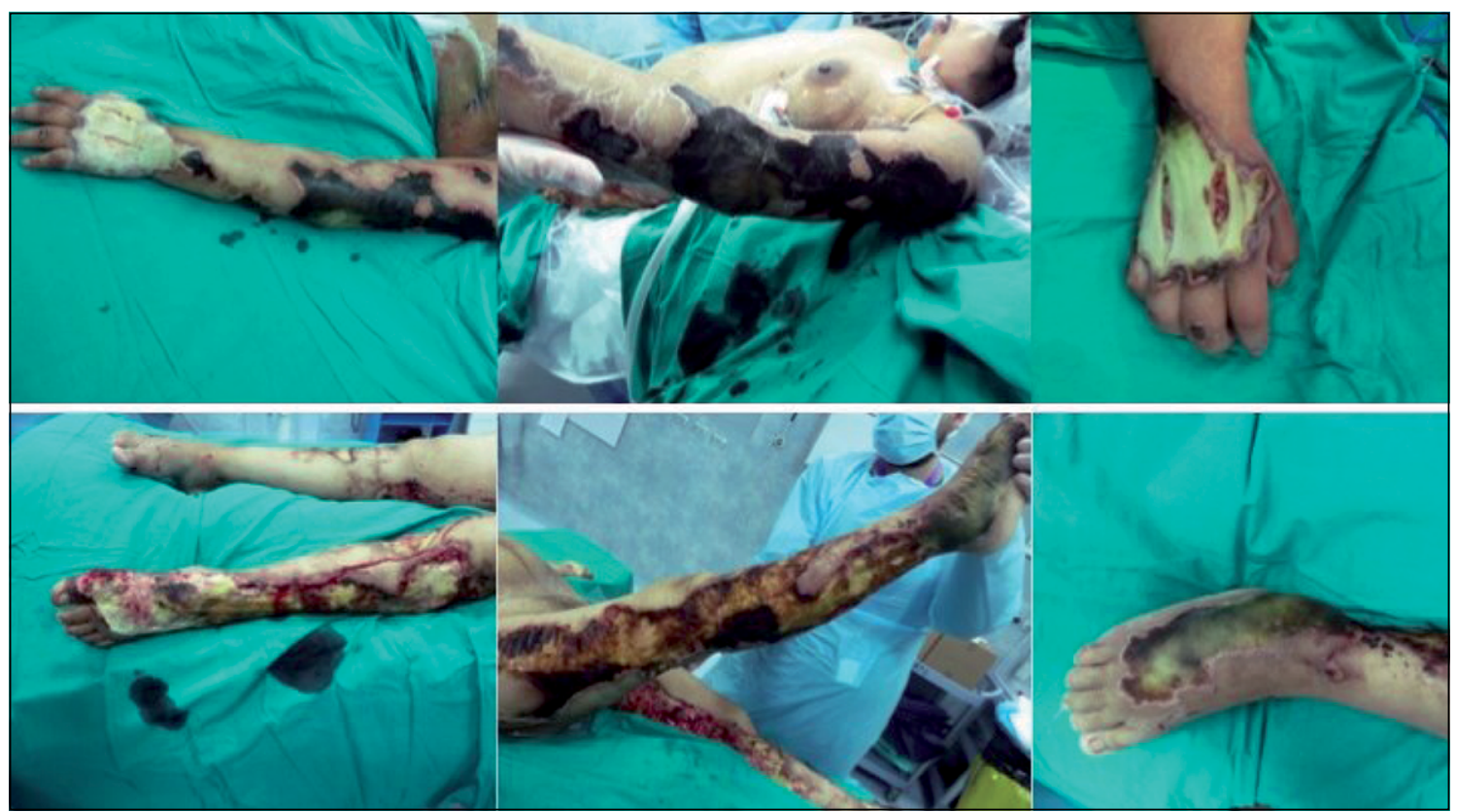

Figura 1. Se observa la extensa necrosis de extremidades superiores e inferiores al momento del ingreso.

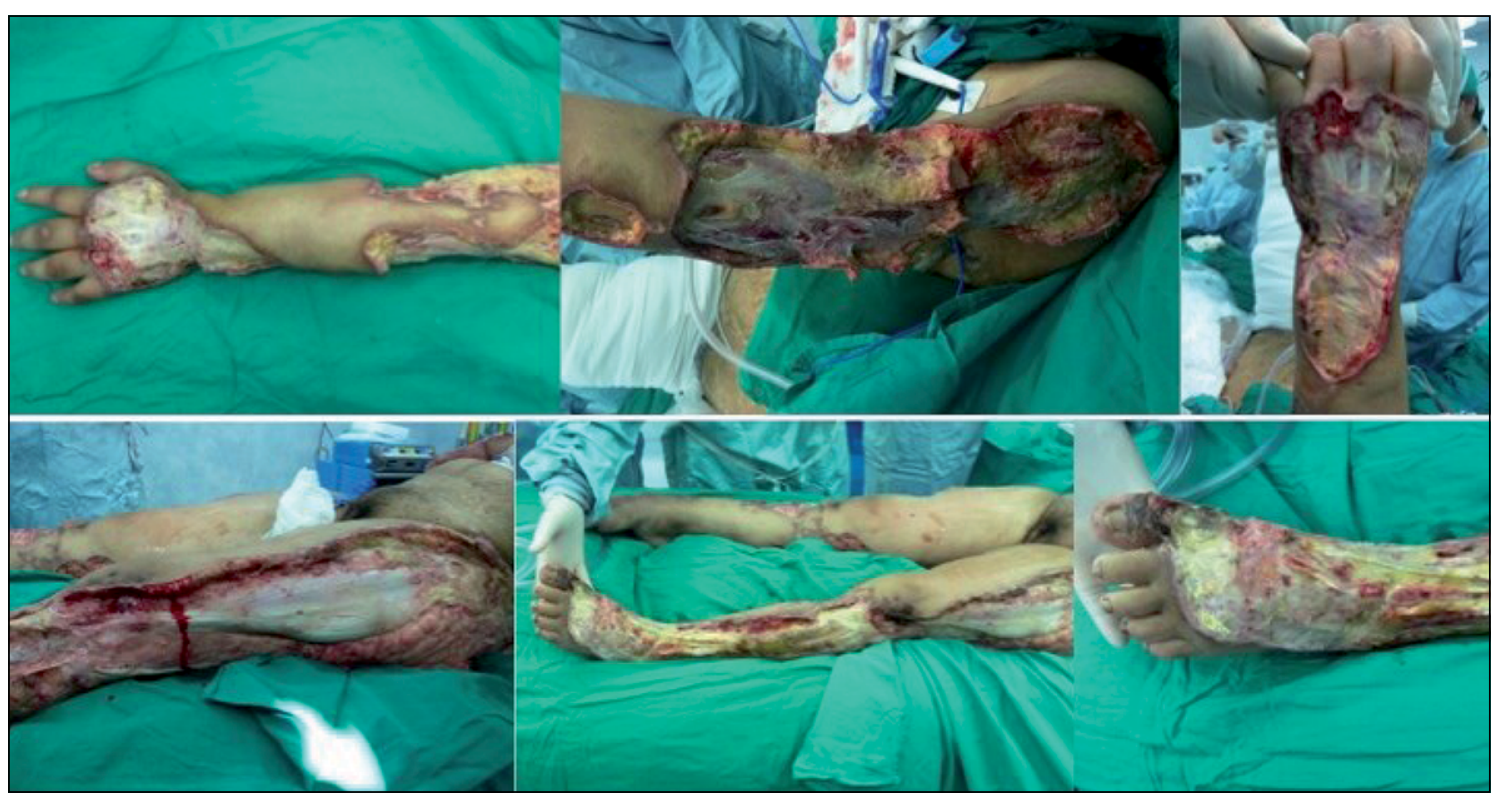

Figura 2. Se observa el defecto de cobertura resultante posterior a la escarectomía, donde se encuentran comprometidas ambas extremidades superiores e inferiores correspondiendo al $27 \%$ de superficie corporal total. 

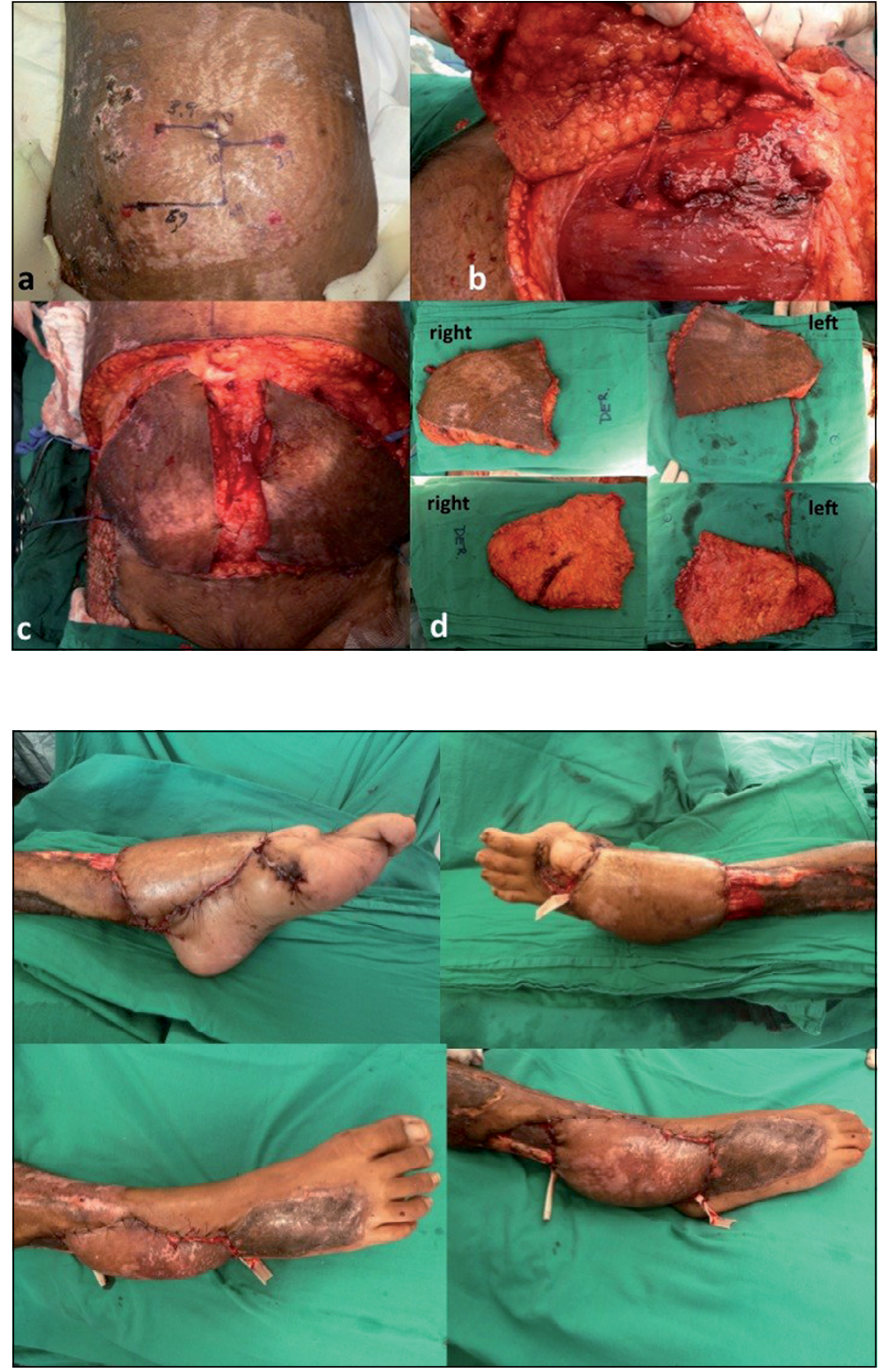

Figura 3. a) Marcación de vasos perforantes periumbilicales con Doppler; b) Disección de vaso perforante de arteria epigástrica inferior en trayecto intramuscular; c) Colgajos DIEP bilaterales previo a la sección de los pedículos; d) Colgajos DIEP posterior a la sección de los pedículos (cara anterior y posterior).

Figura 4. Postoperatorio una semana después de la intervención. Se logra cobertura del defecto articular y tendinoso en ambas extremidades.

\section{Discusión}

La cobertura en el paciente grave con pérdidas cutáneas extensas en general es de una alta complejidad. La determinación del tipo de cobertura cutánea dependerá de la extensión de la pérdida y las zonas expuestas. Frente a la presencia de extensas zonas expuestas en extremidades superiores, como en este caso, el uso de injertos de piel parcial expandido 3:1 parece ser una buena alternativa ya que limita las zonas dadoras reduciendo las áreas cruentas y asegura un mejor prendimiento de estos en desmedro de un peor resultado funcional y estético ${ }^{7}$.

Es sabido que la reconstrucción estándar de la pierna se realiza de acuerdo a la localización del defecto, donde se divide en tercios, correspondiendo el colgajo de músculo gastrocnemio en tercio proximal, colgajo de músculo sóleo para tercio medio y un colgajo microquirúrgico en tercio distal, debiendo adecuarse estos principios a la realidad del paciente, del centro tratante y del equipo quirúrgico en particular $^{8}$. En el caso de nuestra paciente, siguiendo la premisa, dada la ubicación, la existencia de zonas articulares expuestas, la extensión del defecto y 
ante la falta de tejidos locales vecinos al defecto se debió recurrir a la cobertura con colgajos libres como alternativa.

El extenso compromiso cutáneo en ambas extremidades impidió contar con zonas dadoras de colgajos regionales para cubrir este defecto, por otro lado, la importante atrofia muscular de las extremidades inferiores hacía poco adecuado el uso de colgajos musculares libres como por ejemplo el de músculo gracilis, ya que debido a su pequeño tamaño lo haría insuficiente para lograr la cobertura deseada. El uso de otros colgajos musculares libres como el músculo dorsal ancho se descartó debido a que la paciente presentaba importante atrofia muscular generalizada, con pérdida de gran parte de los tendones extensores de ambas manos y presentaba un pie equino izquierdo severo debido a la pérdida de tendones flexores del pie por necrosis por lo cual el uso de este músculo podría traer importantes repercusiones funcionales para la paciente en su período de rehabilitación ${ }^{9,10}$.

Dado lo anterior y tratándose de una paciente puérpera que presentaba flaccidez y excedente cutáneo de la pared abdominal se decide utilizar esta zona dadora de colgajo. Para producir la menor alteración funcional y mantener la prensa abdominal se realiza un colgajo DIEP bilateral el cual aportó la cantidad adecuada de tejido para lograr la cobertura completa del dorso del pie y regiones maleolares peroneas de ambas extremidades. Debido a las condiciones generales de la paciente y para optimizar los tiempos quirúrgicos la cirugía se realizó en un tiempo con dos equipos realizando las microanastomosis en forma simultánea.

El colgajo DIEP está ampliamente descrito para su uso en reconstrucción mamaria y otras localizaciones como cabeza y cuello. El uso de colgajos basados en perforantes y del DIEP en particular, es menos habitual muchas veces por el abultamiento que produce en un lugar donde se requiere de coberturas cutáneas más finas, sin embargo, ha sido comunicado su utilización con éxito en diferentes sitios, tales como extremidades superiores e inferiores $^{11-16}$. En este caso, dado las condiciones generales y locales de la paciente este colgajo resultó ser una excelente alternativa, sin morbilidad en la zona dadora y un resultado adecuado.

\section{Referencias}

1. Murad AA, Jeffers M, Tobin AM, Connolly M. BMJ Case Rep. 2013 Jan 30;2013. pii: ber2012007947. doi: 10.1136/bcr-2012-007947.

2. Iglesias M, Butrón P, León-López DA, García-Mancilla
S, Espino-Gaucin I, Rubio A. Soft tissue reconstruction with omental free flap in complex upper extremity injuries: Report of 13 cases. Microsurgery 2014 Feb 12. doi: 10.1002/micr.22236. [Epub ahead of print].

3. Guerra AB, Lyons GD, Dupin CL, Metzinger SE. Advantages of perforator flaps in reconstruction of complex defects of the head and neck. Ear Nose Throat J. 2005;84:441-7.

4. Koshima I. Soeda S. Inferior epigastric artery skin flaps without rectus abdominis muscle. Br Plast Surg. 1989;42:645-8.

5. Allen RJ, Treece P. Deep inferior epigastric perforator flap for breast reconstruction. Ann Plast Surg. 1994;32:32-8.

6. Blondell PN. One hundred free DIEP flap breast reconstructions: a personal experience. Br J Plast Surg. 1999;52:104-11.

7. Vanwijck R, Kaba L, Boland S, Gonzales, Azero M, Delange A, Tourbach S. Immediate skin grafting of subacute and chronic wounds debrided by hydrosurgery. J Plast Reconstr Aesthet Surg. 2010;63:544-9.

8. Pio Hong, Joon. Reconstructive surgery: Lower extremity coverage. En: Peter Neligan, Plastic Surgery. Third Edition. Seattle, WA, USA: Editorial Elsevier, Saunders, 2013; Vol. IV: Section I: 128-35.

9. Ismaïl M, Boucher F, Chauvel-Picard J, Shipkov H, Braye F, Mojallal A. Sequelae after harvesting latissimus dorsi flap and derivates-Review. Ann Chir Plast Esthet. 2014 Jun 16. [Epub ahead of print].

10. Lee KT, Mun GH. A Systematic Review of Functional Donor Site Morbidity after Latissimus Dorsi Muscle Transfer. Plast Reconstr Surg. 2014 Apr 11. [Epub ahead of print].

11. Van Landuyt K, Blondeel P, Hamdi M, Tonnard P, Verpaele A, Monstrey S. The versatile DIEP flap: its use in lower extremity reconstruction. Br J Plast Surg. 2005;58:2-13.

12. Chan JK, Harry L, Williams G, Nanchahal J. Soft-tissue reconstruction of open fractures of the lower limb: muscle versus fasciocutaneous flaps. Plast Reconstr Surg. 2012;130:284e-95e.

13. Grinsell D, Saravolac V, Rozen WM, Whitaker IS. Pre-expanded bipedicled deep inferior epigastric artery perforator (DIEP) flap for paediatric lower limb reconstruction. J Plast Reconstr Aesthet Surg. 2012;65:1603-5.

14. Tan O. Versatility of the vertical designed deep inferior epigastric perforator flap. Microsurgery 2009;29:282-6.

15. Duffy FJ Jr, Brodsky JW, Royer CT. Preliminary experience with perforator flaps in reconstruction of soft-tissue defects of the foot and ankle. Foot Ankle Int. 2005;26:191-7.

16. Koshima I, Nanba Y, Tsutsui T, Takahashi Y, Itoh S. Perforator flaps in lower extremity reconstruction. Handchir Mikrochir Plast Chir. 2002;34:251-6. 